\title{
Intellectual Entrepreneurship: Theories, Purpose and Challenges
}

\author{
Adebiyi Julius Abosede $^{1} \&$ Adegbemi Babatunde Onakoya ${ }^{2}$ \\ ${ }^{1}$ Department of Business Administration, Faculty of Social and Management Sciences, Olabisi Onabanjo University, \\ Ago Iwoye, Ogun State, Nigeria \\ ${ }^{2}$ Department of Economics, Tai Solarin University of Education, Ijagun, Ogun State, Nigeria \\ Correspondence: Adebiyi Julius Abosede, Department of Business Administration, Faculty of Social and \\ Management Sciences, Olabisi Onabanjo University, Ago Iwoye, Ogun State, Nigeria. E-mail: \\ adebiyi.abosede@yahoo.co.uk
}

Received: July 10, 2013

Accepted: July 30, 2013

Online Published: September 6, 2013

doi:10.5430/ijba.v4n5p30

URL: http://dx.doi.org/10.5430/ijba.v4n5p30

\begin{abstract}
Entrepreneurship and intellectualism are usually seen in different forms, but one can reinforce the other. Intellectual competencies have become quite useful in an increasingly complex context of business activities and thus have the potential of reinforcing entrepreneurship. Entrepreneurship is one of the factors of production. The challenge for intellectual entrepreneurial organizations therefore lies less in the creation of esoteric ideas for the shelves, but collaboration with enabling agents for converting creativity in form of the knowledge assets to innovation and wisdom for it to become more relevant in promoting sustainable economic growth. However, the legal protection of intellectual property rights is sine qua non to successful implementation and long-term entrepreneurship sustainability on the platform of intellectualism.
\end{abstract}

Keywords: intellectualism, entrepreneurship, entrepreneur, academia

\section{Introduction}

Most often, the terms entrepreneur, entrepreneurship and entrepreneurial, are tended to be used interchangeably, whereas each concept denotes specific thing about the individual, group or society undertaking resource utilization to create satisfaction. The term entrepreneur as posited by Clark $(1998,2004)$ is applicable to individuals, organizations and projects. Kuratko (2006) describes the outcome of entrepreneurship as being strategic change management encompassing vision, mission, and core values determination and implementation mechanisms. In effect, the entrepreneur pursues novel processes and methods to take advantage of opportunities through creation of value (Brown $\&$ Ulijn, 2004). The entrepreneurial process is considered a key aspect of the dynamism of economic crisis (renewal) during which less efficient firms fail and are replaced by the more efficient ones in the continuous process of creative destruction (Schumpeter, 1942). Entrepreneurship as a process gives people more jobs, creates new inventions and ideas, increases and/stimulates national income consequently having the potential of affecting economic development (Abosede \& Onakoya, 2013).

The tendency is to ascribe intellectual entrepreneurship to the academia alone especially when viewed from the narrow sense. Johannisson, Kwiatkowski and Dandridge (1999) present in Figure 1 the notion of intellectual entrepreneurship consisting of three constituents made up of intellectualism, entrepreneurship, and the academia. Academic entrepreneurship, in the 1980s flourished as a strategy for commercializing scientific knowledge (Stankiewicz 1994). 


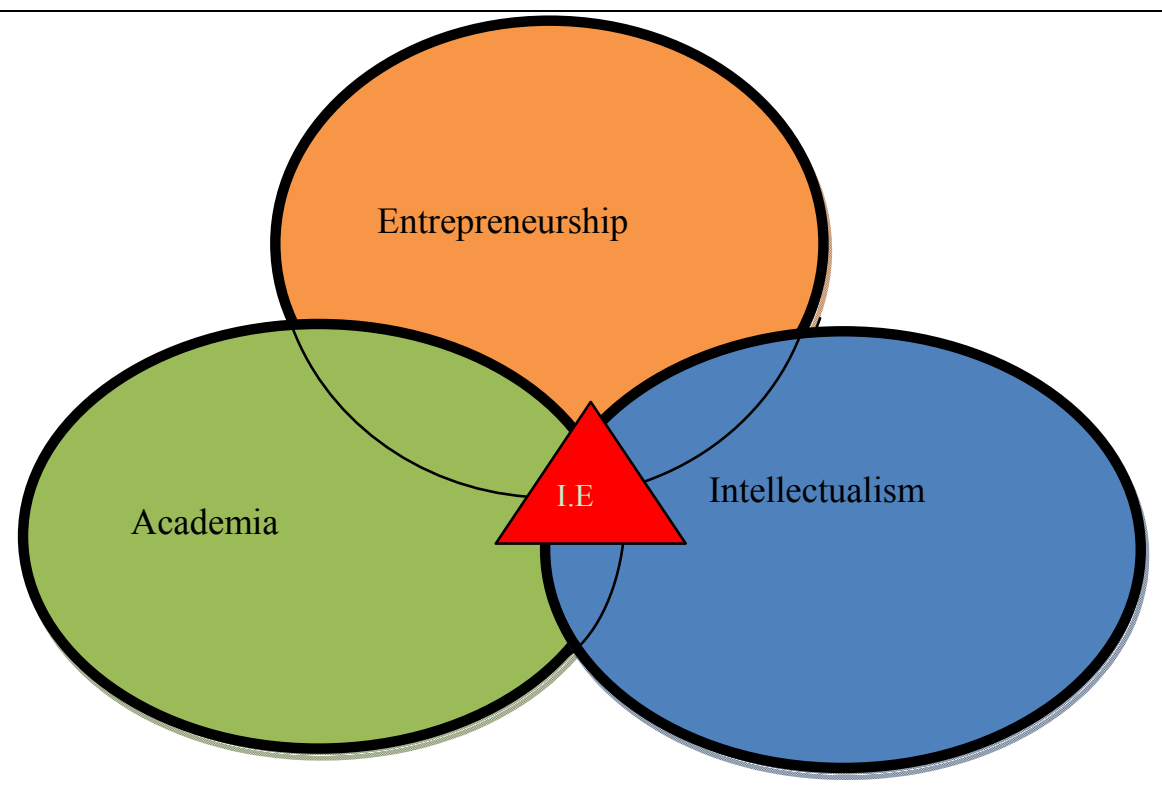

Figure 1. Delineating the notion of intellectual entrepreneurship

Source: Adapted from Johannisson, Kwiatkowski and Dandridge (1999)

Where: I.E = Intellectual Entrepreneurship

Academics, science parks, and entrepreneurship are three closely related phenomena which have often been addressed in research (Roberts, 1991). However, Massey, Quintas, and Wield (1992) contend that the potential of academic/high-tech entrepreneurship is exaggerated. Although intellectualism and high formal (academic) education may intersect as well, many intellectuals are loners.

Intellectualism involves learning, erudition as well as informed and critical thinking. The intellectual is a specific variety of the intelligent practitioner which unlike the general property is strictly associated with reason and thinking (Sowell, 1980). The Random House Dictionary (1987) states that intellectuals rely on intellect rather than on emotions and feelings. Ezioni (1968) identifies three dimensions of an intellectual to be the possession of a broad and diversified knowledge base, critical mindset which reflects thoroughly before taking action and independence of thought. The intellectual primarily uses rational intelligence to resolve conceptual and empirical challenges.

As a concept, intellectual entrepreneurship suggests the application of rationality and intuition within the learning cycle and contextually outside the box. While the entrepreneurial capabilities answer for risky experimentation and resolute action, the intellectual endowments incorporate reflection and conceptualization in the expansion of the frontier of knowledge. In effect, intellectual entrepreneurship requires collaboration with people for the generation of ideas on the one part and the commitment of people with other requisite skills and resources for the realization of a project.

The intellectual and the entrepreneur share a number of characteristics in their organizing function. They both operate independently but work with others only in mutually beneficial relationships or forced collaborations. By this means, the intellectual approaches challenges with analytical skills while the entrepreneur do so with action power. To both intellectuals and entrepreneurs, constant change appears as the normal state of being since they both epitomize the notion of creativity (Chia, 1995).

Intellectual entrepreneurship is creating synergistic relationships among academic disciplines and between intellectuals on and off campus in order to sew seamless connections among disciplines and between the academy and the public and private sectors. Intellectual entrepreneurship is about harnessing, integrating and productively utilizing intellectual energy and talent wherever it is located in order to promote academic, cultural, political, social and economic change. Intellectual entrepreneurship takes advantage of the knowledge assets contained within walls of the university and empower faculty and students to become change agents both internally and externally (Cherwitz and Hartelius 2007).

In furtherance of this proposition, Kwiatkowski (1999) submits that both academics and business people participate contemporaneously in many organizations and environmental settings. In support of this Florida (2002) explains that 
there is a growing army of creative class to which intellectuals and entrepreneurs both belong. The underlying premise on which the intellectual entrepreneurship is premised is that intellect is not limited to the academy and entrepreneurship is not synonymous with business. At the base level, entrepreneurship is the creation of material wealth. However at a more profound level, it is an attitude for expanding the frontier of knowledge globally. This paper seeks to contribute further to the body of knowledge on the purpose, challenges and panacea of intellectual entrepreneurship on the development of entrepreneurial activities in the context of Nigeria.

The rest of the paper is presented as follows: section two reviews the theories of entrepreneurship. In the third section, the purpose of intellectual entrepreneurship is discussed. The challenges of and panacea to intellectual entrepreneurship are discussed in section four with section five concluding.

\section{Entrepreneurship Theories}

The underpinning importance of entrepreneurial behavior for economic development was first identified by Cantillon (1680's - 1734) who categorized the economic agents into landowners, employees and entrepreneurs. While the first and the second groups are passive, the entrepreneurs play the resource coordinating functions in addition to managing uncertainties. Cantillon became the progenitor of the entrepreneurship ideas and its crucial roles in economic theory. In the contemporary literature however the entrepreneur appears to have fizzled out in the various economic theories and models. In the next section, some of the important theories are presented.

\subsection{Neoclassical Economics of Entrepreneurship}

Cantillon $(1755,1931)$ in $18^{\text {th }}$ century was the fore bearer of the entrepreneurship ideas and its crucial roles in economic theory. However, the neoclassical school of thought ignored entrepreneurship as a variable in the theory of the firm (e.g., Baumol 1968). This exclusion as explained by Montanye (2006) was as a result of the need by the neoclassical economists to simplify the basic assumptions. The assumptions neglected the need for a special role for the production factor responsible for risk-bearing, invention / innovation, and coordination of the other factors of production (Schumpeter 1911, 1934). Cosgel (1996) contends that the absence of the entrepreneur in economic theory is due to the increasing emphasis on equilibrium and the mathematical method of economics itself.

Schumpeter however argued for the inclusion of the entrepreneurial function in the formulation of the modern theory of the firm. He posits that when the entrepreneur is successful in generating new ideas and translates such creativity to innovative product and services, the entrepreneur is rewarded with profits temporary monopoly rents. The Schumpeterian entrepreneur pushes the economy away from the equilibrium at the lower level through the introduction of his innovations. He is by being responsible for the disequilibrium becomes a veritable factor in the production function (Montanye 2006). All of these point to the idea that an entrepreneur is a change agent taking risks for his actions while in the same breath meeting the need gap of the people through innovation, creativity and modernization. The next discussion focuses on the concept of risk and uncertainty which is a specialized key function of the entrepreneur.

\subsection{Uncertainty Concept}

The distinction between risk and uncertainty is identified by Knight (1921) as the unique identifier of the entrepreneur. Risk exists when outcome which is insurable, is vague but can be forecast with some degree of probability. However, when the probability of outcomes cannot be predicted uncertainty is said to have arisen. The true uncertainty however arises when the future is unknown and cannot be predicted. Schultz (1980), in support of Knight contends that it was a true uncertainty gives rise to "pure profit" which is the life blood of entrepreneurial pursuit. Entrepreneurs most of the times take measured risk rather than facing uncertainty outright. It is the risk taking posture that aids entrepreneurs in taking advantage of arbitrage. The slant of uncertainty as discussed by the Austrian school is presented in the next section.

\subsection{The Austrian School of Thought}

The Austrian School sharply differed from the neoclassical approach. von Mises contends that the correctness of the entrepreneur's anticipation of uncertain events determines the success or otherwise of his venture. According to the Austrian school, it is the asymmetric and imperfect information at his disposal that prevents the inclusion of the entrepreneurial function into neoclassical models. The dynamics of competition and the uncertainty in the process of entrepreneurial discovery, which is the driving element of the Austrian school, tends systematically move the firm towards, rather than away from the path to equilibrium Khalil (2007).

The Australian school therefore dwells on the drivers of entrepreneurship which entails catching up with the gaps in the environment through creative innovations. In consonance with this position, Kirzner introduced the key concepts 
of "spontaneous learning", "alertness" and "entrepreneurial discovery" which gives the entrepreneur a place in the production milieu. The knowledge entrepreneurship is discussed in the next section.

\subsection{The Knowledge Entrepreneurship Model}

Harvey and Knight, (1996) describe knowledge entrepreneurship as a genre of intellectual entrepreneurship which focuses on improving research and throughput of knowledge. This differs from the conventional economic entrepreneurship which is geared primarily at the realization of monetary profit. It is therefore the contention of these authors that knowledge entrepreneurship is the most suitable form of entrepreneurship for not-for-profit educators, researchers and educational institutions.

Senges (2007) using McDonald (2002) proposes the following specific set of factors which directly shape the knowledge entrepreneurship ability (Figure 2). The figure brings to the fore the roles in play:

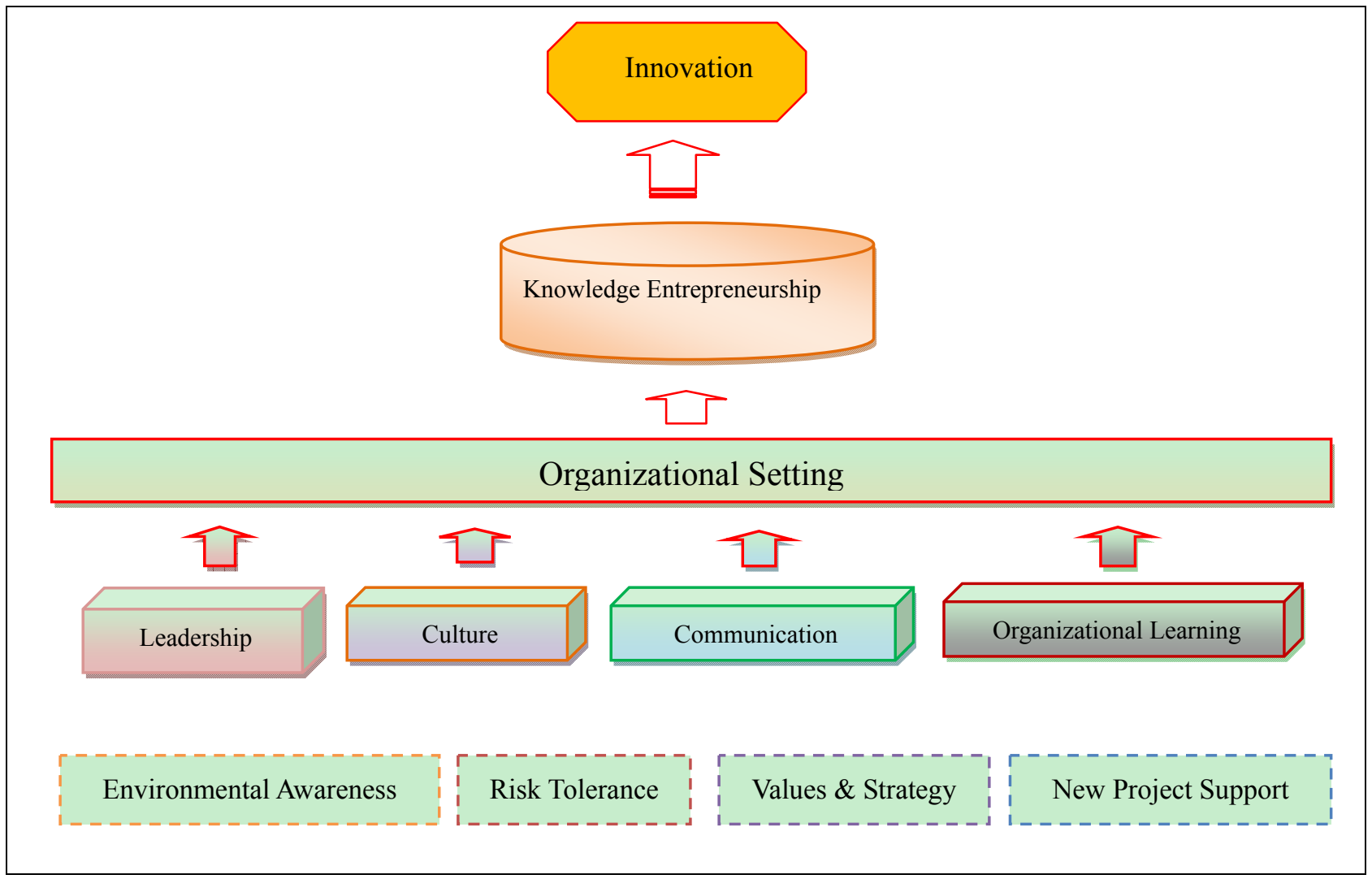

Figure 2. Model of knowledge entrepreneurship

Adapted from McDonald (2002) and Senges (2007)

Environmental Awareness: This portrays the internal and external environmental practices with which the firm collects information. Cornwall and Perlman (1990) underscore its importance by proposing that the scanning of the environment should be fundamental as part of ongoing strategic planning function of every manager.

Risk Tolerance: The organizations should be imbued with risk taking attitude which is a critical requirement in the pursuit of (Kuratko, 2006). It is important that expected values for the different risk levels can be determined for better decision making on the part of the entrepreneur.

Values and Strategy: These portray long term strategic planning which encompasses the organization's culture of envisioning and scouting for new developments. This involves doing a now and future positioning to properly accommodate competitions and changing nature of the business environment (Senges, 2007).

New Project Support: This driver-variable, attests to the inclination of management to support and finance new ideas. It refers to the extent to which the organization has institutionalized innovation as a vehicle of institutional development (McDonald, 2002).

The organizational setting represents the basic structure of the organization including its size, type of institution, business model, history and historic approach to innovation. The organizational conditions (current leadership and 
organizational culture) determine the likelihood of knowledge entrepreneurship occurrence. The culture of the organizational is critical to the understanding of the dynamics of the growth of the organization. The attitude towards organizational learning and values like innovativeness, competitiveness and entrepreneurship are considered critical to success. The style of communication and the richness of communication channels are significant influencers of organizational cohesion. In addition, the completeness of information being communicated which eliminates ambiguity is in the opinion of McDonald (2002) and Senges (2007) considered critical to organizational success.

The knowledge entrepreneurship improves visioning, innovation and creativity. It thereby indirectly improves the performance of the organization. Long term ability of the organization to adapt and survive in the submission of Cornwall and Perlman (1990), is the most important responsibility of the entrepreneur. The dynamic nature of the environment directly and indirectly accentuates competition therefore fosters business performance. This is also shapes the creative entrepreneurship which is the next presentation.

\subsection{Creative Entrepreneurship}

The creative sectors which products are an intrinsic part of the knowledge economy include software, music publishing and entertainment, creativity. Although considered to be the most important resource, has received relatively little attention. The creation and exploitation of intellectual capital which is the focus of the creative entrepreneur differs from that of the typical business entrepreneur. The creative entrepreneur invests in talents by setting up a business as self-employed or in one of the creative industries. The entrepreneurs in the creative economy operate like Say's (1845) original function as coordinator of resources. In addition, the creative entrepreneur unlocks the wealth that lies within him and manages such inventions in the true capitalist's mode in order to engender more wealth (Howkins 2001).

The advent of the knowledge economy meant that the old rules of manufacturing-based business needed to be reconsidered. Whereas, the traditional economists concentrate on tangible capital input and conventional goods and services. The new economist focus on intangible ideas and outputs e.g. software (Drucker, 1969). In order to manage creativity, it is crucial that the timing of harnessing the non-rivalrous ideas and the assertion of intellectual property right be appropriate. The intellectual property right is discussed in the next section.

\subsection{Intellectual Property Rights and the Knowledge Spillover Theory}

The literature is replete with disputation on the optimal strength and scope of patent protection. The argument for the protection is predicated on the endogenous growth theory which posits that innovation drives economic growth in the long run (Aghion \& Howitt, 1992; Grossman \& Helpman, 1991 and Romer, 1990). The rationale is that stronger intellectual property protection stimulates investment in knowledge creation which is the basis of sustainable economic growth (Allred \& Park 2007; Baro \& Sala-I-Martin, 2004).

Gould and Gruben (1996) do not support the hypothesis that stronger protection is always better but provided evidence of an inverted-U-shaped relationship. Nordhaus (1969) stresses that the dynamic innovation gains is offset by losses arising from static efficiency which occur from takeoff constraints. Another argument against the efficacy of patent protection is the rent - seeking strategy of inventors who seek to garner patents on all potentially valuable knowledge, without the intention to commercialize the innovation. The objective is to capture rents once an idea is commercialized by another party and generates profits. This results in sub-optimal economic development.

Given all these theories, it suggests that an entrepreneur has the chance of survival through intelligence premised on the ability to properly evaluate the environment for opportunities. This is the basis for the next discussions on the purpose of intellectual entrepreneurship which is presented in the following section.

\section{Purpose of Intellectual Entrepreneurship}

The intellectual entrepreneur is relevant in many facets. These can be seen in the key drivers of entrepreneurship. These include, among others,

(i) Sustaining Entrepreneurial Education: Intellectual entrepreneurship offers an authentic philosophical foundation for sustaining cross-campus entrepreneurship education. Cherwitz and Darwin (2005) posit that the purpose of intellectual entrepreneurship is to nurture and educate "citizen-scholars" throughout the citadel of learning.

(ii) Harnessing Resources: Intellectual entrepreneurship is predicated upon the knowledge assets contained within the walls of the university. This empowers faculty and students to become change agents within and outside the campus (Cherwitz and Hartelius 2007). In recognition of the rich humanistic traditions upon which the university is based, intellectual entrepreneurship harnesses the core philosophy of western education and transforms the master-apprentice-entitlement paradigm into one of invention, ownership, responsibility, collaboration, and 
implementation (Cherwitz and Hartelius 2007). Intellectual entrepreneurship has the advantage of further expanding the utility function of resources thereby raising resource value.

(iii) Shaping the Business World: Intellectual entrepreneurship influences the contemporary world through its research findings and innovative ideas. For the higher institutions to be relevant to the larger world, intellectual entrepreneurship is required to wed the academic mission with the society.

\section{Challenges of and Panacea to Intellectual Entrepreneurship}

For the purpose of intellectual entrepreneurship to be achieved, there are many challenges that need be addressed. Some of these challenges are;

(i) Personality Traits Challenges: There is no one definitive profile for becoming a successful intellectual entrepreneur. Intellectual entrepreneurs come in various gender, race, ages and income levels. They also differ in education and experience. However, research indicates that most successful entrepreneurs share certain personal attributes including: dedication, creativity, determination, leadership, flexibility, self-confidence, passion and smarts (Acs, 2006). Conversely, most academics are lacking in some of these traits. Coon (2008) defines personality traits as the stable qualities that a person demonstrates in most situations. Every entrepreneur has these qualities in different degrees. Where the entrepreneur is lacking in specific area(s), someone with the requisite attributes can be hired to perform the tasks. The most essential stratagem is to be aware of strengths and to build on them.

(ii) Conventions: Academics are guided by principles and conventions as to how to teach, publish, conduct research and behave at professional conferences. This is augmented by each academic discipline which supplement with its own set of principles. The specific variations indicate what is considered valid knowledge in the field and what roles and status are assigned to its members. All these may negatively constrain the facilitation of intellectual entrepreneurial collaboration with other academic and corporate researchers (Clemens \& Cook 1999). The town and the gown should have a way of overlapping without mortgaging the academic conventions.

(iii) Change Management: Institutional change is a sustained proposition which requires more than good ideas and innovative programs. Efforts at transforming academia via entrepreneurship have met with stiff resistance. The humanistic ideals which forms the foundation of higher learning, have presented difficulties at the altar of the expediencies of economic pursuit. This is something perceived by many as adversative to the liberal arts although both the academia and entrepreneurship tradition a share certain commonalities: garnering faculty support, providing visionary leadership and developing innovative curricula. However, many universities have also found that defining intellectual entrepreneurship in a way unique to their intended purposes and institutional culture is critical to successful operation and long-term entrepreneurship sustainability.

(iv) Legal Protection of Intellectual Property Rights: Businesses especially the small ones can thrive in an environment that promotes respect for individual property rights and provides an institutional legal system to protect such rights. In the absence of property rights, the incentive to create and invest is stifled. The law needs to look after intellectual property for intellectual entrepreneurship to thrive. Innovations are required to be legally protected through copyrights, trademarks and patents if entrepreneurs are to take the risks required to invest in new products and methods (World Bank, 2006).

(v) Creating a Business Culture: The governments are enjoined to engender intellectual entrepreneurship by easier for intellectuals (individuals and organizations) to learn business skills and by honoring outstanding entrepreneurial achievements.

(vi) Funding R\&D and Innovations: Many intellectual entrepreneurs struggle to find the capital to finance research and development and even research findings or starting a new business. There are several financing options and sources available for the entrepreneur to explore. These include, in addition to the financial institutions, venture investors (capitalist), micro finance and government grants.

(vii) Strategic Collaborations: Many in the academia are responsible for their own intellectual isolation. For many there is safety in small numbers in lieu of engagement. Journal articles, books and other academic materials are produced for the minority (in-breeding). The community outside the academy is abandoned resulting in a yawning gap between the town and gown. A broad intellectual and philosophical platform is required for change through entrepreneurship to be manifest. The change platform must be all inclusive, diversified and must reflect the humanistic foundation upon which the academic ethos are predicated. 


\section{Conclusion}

Entrepreneurs innovate and clearly, innovation is considered a critical driver of economic growth in the formulation of the endogenous growth theory. The entrepreneur, in his continuous exploration always search for new vistas, responds to it and exploits such opportunity (Drukker, 1985). The commercial introduction of many products and services hitherto unknown, and the opening up of new markets have been brought about by entrepreneurs. The intellectual entrepreneurs, from the peer collaborative exploits and in some cases with sponsorship of the government have introduced many innovations that have revolutionized how people live and work. From the automobile to the airplane to personal computers, intellectual entrepreneurs with dreams and determination have been in the fore front of the developments of these commercial innovations.

The challenge for intellectual entrepreneurial organizations therefore lies less in the creation of esoteric ideas for the shelves. As intellectual entrepreneurs continue to strive for frontier enlargement, their long-terms success will be determined by their ability to provide relevant innovative ideas to the external world, jeopardizing the academic culture that sets it apart. This is an authentic agent of the humanistic ideal and spirit which provide a philosophical structure inherent to the act of higher education.

\section{References}

Abosede, A. J., \& Onakoya, A. B. (2013). Entrepreneurship, economic development and inclusive growth. International Journal of Social sciences and Entrepreneurship (IJSSE), 1(3), 375-387. Retrieved from http://www.ijsse.org

Acs, Zoltan J. (2006). How is entrepreneurship good for economic growth? Innovations, MIT Press Journal (Winter), 97-107. Retrieved from http://www.mitpressjournals.org/doi/pdf/10.1162/itgg.2006.1.1.97

Alvarez, S.A., \& Busenitz, L.W. (2001). The entrepreneurship of resource-based theory. Journal of Management, 27, 755-775. http://dx.doi.org/10.1177/014920630102700609

Beckman, G. D., \& Cherwitz, R. A. (2008). Intellectual Entrepreneurship as a Platform for Transforming Higher Education. Metropolitan Universities, 19(3), 88-101.

Brown, T. E., \& Ulijn, J. M. (2004). Innovation, entrepreneurship and culture: the interaction between technology, progress and economic growth. Cheltenham, UK; Northampton, Mass., USA: E. Elgar Pub.

Cantillon, R. (1931) (original 1755). Essaisur la nature du commerce en general, edited and translated by H. Higgs. London: McMillan.

Cherwitz, R. A., \& Darwin T. (2005). Crisis as opportunity: An entrepreneurial approach to productivity in higher education. In J. E. Miller and J. Groccia (Eds.), Enhancing Productivity in Higher Education (pp.58-68). Bolton, MA: Anker Publishing.

Cherwitz, R. A., \& Hartelius E. J. (2007). Making a “Great'Engaged' University” requires rhetoric. In J. Burke (Ed.), Fixing the Fragmented University: Decentralization with Direction (pp.265-88). San Francisco: Jossey-Bass.

Chia, R. (1995). From modern to postmodern organizational analysis. Organization Studies, 16(4), $579-604$.

Clark, B. R. (1998). Creating entrepreneurial universities: organizational pathways of transformation (1st ed.). Oxford; New York: Published for the IAU Press by Pergamon Press.

Clark, B. R. (2004). Sustaining change in universities. Continuities in case studies and concepts: Open University Press.

Clemens, E. S., \& Cook, J. M. (1999). Politics and institutionalism: Explaining durability and change. Annual Review of Sociology, 25, 244-266. http://dx.doi.org/10.1146/annurev.soc.25.1.441

Cornwall, J. R., \& Perlman, B. (1990). Organizational entrepreneurship. Homewood, Ill.: Irwin.

Cosgel, M. M. (1996). Metaphors, Stories, and the Entrepreneur in Economics. History of PoliticalEconomy, 28(1), 57-76. http://dx.doi.org/10.1215/00182702-28-1-57

Drucker, P. F. (1985). Innovation and Entrepreneurship. New York: Harper Business.

Florida, Richard. (2002). The Rise of the Creative Class. And how it's Transforming Work, Leisure, Community and Everyday Life. New York. Basic Books.

Harvey, L., \& Knight, P. (1996). Transforming higher education. Buckingham [England]; Bristol, Pa.: Society for Research into Higher Education: Open University Press. 
Howkins, J. (2001). The Creative Economy: How People Make Money from Ideas, 129.

Johannisson, B., Kwiatkowski, S., \& Dandridge, T. (1999). Intellectual entrepreneurship: Emerging identity in a learning perspective. In Stefan Kwiatkowski and Leif Edvinsson (Eds.), Knowledge Café for Intellectual Entrepreneurship (pp.29-46). Warsaw: Leon Kozminski Academy of Entrepreneurship and Management.

Khalil, E. L. (2007). Entrepreneurship and economic theory. In M. Weber (Ed.), Handbook of Whiteheadian Process Thought. Frankfurt: Verlag.

Knight, F. (1921). Risk uncertainty and profit. New York: Houghton-Miffin.

Kuratko, D. F. (2006). Entrepreneurship: theory, process, practice (7th ed.). Mason, OH: Thomson South-Western.

Kwiatkowski, Stefan. (1999). A train named 'adventure for thought'. In Stefan Kwiatkowski and Leif Edvinsson (Eds.), Knowledge Café for Intellectual Entrepreneurship (pp.177-202). Warsaw: Leon Kozminski Academy of Entrepreneurship and Management.

Massey, D. Quintas, \& Wield, D. (1992). High-Tech Fantasies. Science Parks in Society, Science and Space. London: Routledge.

McDonald, R. E. (2002). Knowledge entrepreneurship: linking organizational learning and innovation. University of Connecticut.

Montanye, J. A. (2006). Entrepreneurship. The Independent Review, 10(4), 549-571.

Onakoya, A. B., \& Abosede, A. J. (2013). The common thread amongst entrepreneur, manager and capitalist: A theoretical approach. International Journal of Social sciences and Entrepreneurship, 1(3), 481-496.

Say, J. B. (1845). A Treatise on Political Economy ( $4^{\text {th }}$ ed.), translated by C. R. Prinsep. Philadelphia: Grigg \& Elliot.

Schumpeter, J.A. (1934). The theory of economic development: an inquiry into profits, capital, credit, interest, and the business cycle. Harvard University Press, Cambridge, MA.

Schumpeter, J.A. (1942). Capitalism, socialism, and democracy. New York: Harper and Row.

Senges, A. (2007). Knowledge entrepreneurship in universities: Practice and strategy in the case of internet based innovation appropriation.

Sowell, T. (1980). Knowledge and Decisions. Basic Books.

The World Bank. (2006). Doing Business 2007: How to Reform, A co-publication of the World Bank and the International Finance Corporation. Retrieved from www.worldbank.org 